\title{
Prevalence of Risk Behaviors among U.S. Muslim College Students
}

\section{Sameera Ahmed, Ph.D.}

The Family \& Youth Institute, Canton, MI, USA, and

Department of Psychiatry and Behavioral Neurosciences

Wayne State University, Detroit, Michigan USA

Wahiba Abu-Ras, Ph.D.

School of Social Work

Adelphi University, Garden City, New York USA

\author{
Cynthia L. Arfken, Ph.D. \\ Department of Psychiatry and Behavioral Neurosciences \\ Wayne State University, Detroit, Michigan USA
}

\section{Abstract}

Limited data exists on alcohol, illicit drug, tobacco, gambling, and non-marital sexual intercourse among Muslim college students; behaviors which are either prohibited or strongly discouraged in Islam. To provide preliminary baseline data, we assessed prevalence of these risk behaviors using a U.S. 2001 national college survey. Of the 10,401 students surveyed, 135 (1.3\%) reported they were raised in Muslim families. The past year prevalence of risk behaviors among the 135 students was $46.2 \%$ for alcohol, $24.6 \%$ for illicit drug use, $37.3 \%$ for tobacco use, and $30.4 \%$ for gambling. Of the never married students, $53.8 \%$ reported ever having had sexual intercourse. Gender differences were significant for tobacco use and gambling. Most Muslim students (58.5\%) reported engaging in at least one risk behavior during the past year, of whom a majority (77.6\%) engaged in two or more behaviors. In multivariate analyses, higher religiosity was protective against any past year risk behavior. These findings provide critical baseline data on risk behaviors among Muslim students. They also underscore the need for updated information and prevention programs. 
Keywords: Muslim, college, risk, alcohol, illicit drugs, tobacco, gambling, sexual intercourse, protective factors, religion, Islam, emerging adult

College traditionally occurs during the transition from adolescence to adulthood and may be associated with changes in behavior, including risk behaviors (Boyd, McCabe, \& Morales, 2005). Risk behaviors refer to those behaviors which have the potential to negatively impact the psychosocial aspect of successful adolescent development (Jessor, 1991). Risk behaviors, such as alcohol and drug use, can have long term negative impact on public health and have been associated with negative mental health outcomes for the individual (Glied \& Pine, 2002; Lawrence, Mitrou, Sawyer, \& Zubrick, 2010; Mokdad, Marks, Stroup, \& Gerberding, 2004). Despite potential negative impact of risk behaviors, it is theorized that engaging in such behaviors are often purposive and may serve a number of functions such as increasing peer acceptance, assisting in individuation from family as well as community, and coping with anxiety (Jessor, 1991). Thus, risk behaviors are rarely isolated but are often interrelated and functional, highlighting the need for prevention efforts to focus on lifestyle rather than individual risk behavior (Jessor, 1991).

Such a conceptualization of risk behavior may be particularly helpful in understanding religious minority emerging adults. As a religious minority in the U.S., American Muslim college students may encounter and navigate between multiple groups' behavioral expectations (i.e., societal, religious, and cultural) as well as experience additional stressors (e.g., discrimination) (Ahmed, 2012). These stressors coupled with a decrease in parental monitoring, common among college students, may result in an increase in the prevalence of risk behaviors among Muslim college students. Previous research suggests differences in prevalence of risk behaviors among ethnic minorities (Factor, Kawachi, \& Williams, 2011), which could potentially be extended to religious minorities.

However, many young people do not engage in risk behaviors due to the buffering effects of protective factors. Religious involvement and religiosity, across religious affiliations, has found to serve as a protective factor against risk behaviors such as substance use (Ghandour, Karam, \& Maalouf, 2009; Luczak, Corbett, Oh, Carr, \& Wal, 2003; Luczak, Shea, Carr, Li, \& Wall, 2006; Mason \& Windle, 2002; Michalak, Trocki, \& Bond, 2007). Still, it is also possible that religiosity may simultaneously serve as both a protective and risk factor, as evidenced by Zaleski and Schiaffino (2000), who observed that increased religious identification protected against initiation of sexual activity but resulted in increased risk of unprotected sex among those who were sexually active.

Currently, scant data exist on the prevalence of risk behaviors among U.S. Muslim college students. In our review of published literature, we found studies on risk behaviors of middle and high school Muslim students in Western 
Europe (e.g., Amundsen, Rossow, \& Skurtveit, 2005; Chédebois et al., 2009; Jayakody et al., 2011), but none on college students. The limited information that exists suggests that Muslim students report low prevalence of most behaviors (e.g., Amundsen et al., 2005; Chédebois et al., 2009; Jayakody et al., 2011), with female Muslim students reporting even lower prevalence than male Muslim students (e.g., Islam \& Johnson, 2003). Furthermore, previous research did not explore whether Muslim engagement in risk behaviors were isolated incidents of risk, or a cluster of behaviors, as suggested by Jessor (1991). Only one study, to our knowledge, explored the protective influence of Islam on a risk behavior in Western nations (Islam \& Johnson, 2003).

\section{Islam, Muslims and Risk behaviors}

Alcohol and Drug Use. Alcohol use is strictly prohibited in Islam and any use would be considered risky. However, alcohol use in the U.S. is prevalent with $63.3 \%$ of fulltime U.S. college students reporting past month use (Substance Abuse and Mental Health Services Administration [SAMSHA], 2010), with males reporting greater prevalence than females (O’Malley \& Johnston, 2002). Our previous work using secondary data analysis of a large representative college survey found $46.6 \%$ of Muslim college students drank alcohol in the past year (Abu-Ras, Ahmed, \& Arfken, 2010). However, in a pilot respondent-driven sampling study of Muslim students at one university, 9\% reported lifetime alcohol use (Arfken, Ahmed, \& Abu-Ras, 2013). The differences may reflect temporal trends, characteristics of the sample, or the context of one university. To the authors' knowledge, there are no other studies on the prevalence of alcohol use among Muslim college students in the U.S.

Similar to alcohol, illicit drug use is prohibited in Islam and any use by a Muslim is considered risky behavior. Among U.S. college students, $22.0 \%$ of full time college students reported using illicit drugs at least once in the past month (SAMHSA, 2010), with use higher among males (Johnston, O'Malley, Bachman, \& Schulenburg, 2012). To the authors' knowledge, there are no studies on illicit drug use among U.S. Muslim college students. The most comparable study on illicit drug use among Muslim religious minorities living in Western countries was conducted in Glasgow, Scotland among a cohort of South Asian high school students and their classmates (Bradby \& Williams, 2006). Of the South Asians in the sample $79 \%$ of students identified as Muslim. Four years after the initial survey, $29 \%$ of the males and $18 \%$ of the females (aged $18-20$ years old), reported lifetime illicit drug use (Bradby \& Williams, 2006). However, there is no mention if the participants were enrolled in college.

Tobacco Use. Within Islam, tobacco use can be considered a risk behavior 
as religious scholars' views on tobacco use range from prohibited to strongly disliked (makruh). Anecdotally, due to the growing knowledge of the negative health impact of tobacco, scholars are increasingly prohibiting tobacco use. Past month cigarette use among U.S. full time college students was $24.8 \%$ (SAMHSA, 2010), with no difference observed between genders (Johnston et al., 2012). Our pilot respondent-driven sampling of U.S. Muslim college students at one university found $50 \%$ had ever consumed tobacco in some form, including cigarettes and waterpipe (Abu-Ras, Ahmed, \& Arfken, 2012). In the above mentioned study on South Asian Muslims from Glasgow, Scotland, 24\% of males and $14 \%$ females reported being current smokers (Bradby \& Williams, 2006).

Gambling. In Islam, any form of gambling is prohibited and considered a risk behavior. Researchers have referred to gambling as an emerging risk behavior among American college students, with a past year prevalence ranging from $35 \%$ to $42 \%$, with males reporting greater prevalence (Atkinson, Sharp, Schmitz, \& Yaroslavsky, 2012; LaBrie, Shaffer, LaPlante, \& Wechsler, 2003). To the authors' knowledge, there are no studies investigating gambling behavior among Muslim college students in the U.S. or Europe.

Sexual Behaviors. In Islam any form of non-marital intimacy, including sexual intercourse, is prohibited and considered a risk behavior. In the U.S., the lifetime prevalence of non-marital sexual intercourse was $76 \%$ of college students according to one study; however gender differences were not reported (Higgins, Mullinax, Trussell, Davidson, \& Moore, 2011). To the authors' knowledge, there are no studies reporting the lifetime prevalence of nonmarital sexual intercourse among U.S. or European Muslim college students.

\section{Objectives}

The focus of this study is to address the current gap in literature on the prevalence of risk behaviors among U.S. Muslims college students by establishing a baseline for more detailed future research. We expand upon our previous analysis examining alcohol use among U.S. Muslim college students (Abu-Ras et al., 2010) to explore illicit drug use, tobacco use, gambling, and non-marital intercourse. Based upon the literature among younger European Muslim students, we hypothesize: (a) that the prevalence of risk behaviors among U.S. Muslim college students will be low (b) that the prevalence of risk behaviors among female Muslim college students will be lower than males, (c) those who engage in risk behavior are more likely to engage in more than one risk behavior, and (d) students reporting religious activities as important will have lower prevalence of risk behaviors. 


\section{Method}

\section{Survey}

For this analysis, we used data from the 2001 Harvard School of Public Health College Alcohol Study's (CAS) public access database (Wechsler, 2001, http:// www.icpsr.umich.edu). The database contains surveys from a national sample of students at accredited four-year colleges and universities (119 colleges in 38 states and the District of Columbia). Additional information regarding sampling and methodology are available elsewhere (Wechsler, Lee, Kuo, \& Lee, 2000b; Wechsler, Lee, Kuo, Seibring, Nelson, \& Lee, 2002a; Wechsler, Lee, Nelson, \& Kuo, 2002b; Wechsler, Nelson, Lee, Kuo, Seibring et al., 2003).

\section{Measures}

The 2001 CAS survey included self-reported measures of alcohol, tobacco, illicit drug use, gambling, and sexual behaviors. The survey also included information on religious heritage of the students and one question on religiosity. Demographic measures were also used to contextualize the findings.

Demographic variables. Variables assessed included: age, gender, marital status, ethnicity and living arrangements. Racial identification was limited to one of the following choices: White, Black/African American, Asian/Pacific Islander, Native American, and Other. Ethnicities, such Arab or Persian, were not a choice for participants. Living arrangements were assessed by asking participants, "With whom do you currently live?" Participants could select one or more of the following responses: alone, roommates or housemates, spouse or partner, parents or other relatives.

Religious heritage and religiosity. Religious heritage was determined based on the participant's response to the question, "In what religion were you raised?" The answers included six categories: "None", "Catholicism," "Judaism", "Islam", "Protestantism", and "Other". We refer to students who answered "Islam" as Muslim students and students who responded with any other category as Non-Muslim students. No questions were asked about current affiliation or specific religious behavior. Religiosity was assessed based on the participant's self-report on the importance of participating in religious activities in college with answers range from "Very Important" "Important", "Somewhat Important" to "Not at all Important". No other question in the survey assessed religiosity.

Alcohol. Participants were asked, "When did you last have a drink (that is more than just a few sips)?" The questionnaire instructed participants to define a "drink" in equivalent amounts of alcohol: a $12-\mathrm{oz}(360-\mathrm{mL})$ bottle or can of beer, a 4-oz (120-mL) glass of wine, a 12-oz $(360-\mathrm{mL})$ bottle or can of wine 
cooler, or a shot $(1.25 \mathrm{oz}$ or $37 \mathrm{~mL})$ of liquor, either straight or in a mixed drink. Possible responses included: "I have never had a drink"; "not in the past year"; "more than 30 days ago, but in the past year"; "more than a week ago, but in the past 30 days"; and "within the last week". For the purpose of this study, the responses were collapsed into the following categories: ever, past year, never. In addition, participants were also asked "How old were you when you first drank alcohol regularly." Three Muslim students did not answer the alcohol use question.

Illicit drug use. Illicit drug use was assessed by asking participants "How often, if ever, have you used any of the drugs listed below?" Participants were specifically asked about the following substances: marijuana, crack or other forms of cocaine, barbiturates (e.g. Seconal, Nembutal, downs, or Yellow Jackets), Ritalin/Dexedrine/Adderall, other amphetamines (e.g. methamphetamines, crystal meth, speed, uppers, ups), tranquilizers (e.g. Valium, Librium, Xanax, Ativan, Klonopin), heroin, other opiate-type prescription drugs (e.g., Codeine, Morphine, Demerol, Percodan, Percocet, Vicodin, Darvon, Darvocet), LSD, other psychedelics or hallucinogens (e.g., mushrooms, mescaline, or PCP), ecstasy (MDMA), other "party drugs" (e.g., Ketamine, Special K, GHB), anabolic steroids (either injections like Depo-testosterone or Durbolin, or pills like Anadrol, Dianabol, or Winstrol), and other performance-enhancing drugs (e.g., growth hormone, diuretics, fluid pills, ephedrine). Participants were instructed not to include drugs that were being taken under physician supervision. Information on marijuana use was obtained by asking participants, "How often, if ever, have you used marijuana", and "How old were you when you first used marijuana." For all illicit drugs, possible responses included: never used, used but NOT in past 12 months, used but NOT in the past 30 days, used in the past 30 days. For the purpose of this study, the responses were collapsed into the following categories: ever, past year, and never. Eight Muslim students did not answer the question on illicit drugs but all Muslim students answered the questions on marijuana. The eight Muslim students with missing information on illicit drugs reported that they had not used marijuana.

Tobacco use. Tobacco use was measured by asking participants "How often, if ever, have you used any of the drugs listed below?" Participants were asked about their use of the following forms of tobacco: cigarettes, cigar, pipe tobacco, bidis and chewing tobacco, dip, or snuff. Waterpipe use was not included. Participants were also asked specifically about their cigarette use. "How often, if ever, have you used cigarettes," and "How old were you when you first used cigarettes." Possible responses for tobacco use were: never used, used but NOT in past 12 months, used but NOT in the past 30 days, used in the past 30 days. For the purpose of this study, the responses were collapsed into the following categories: ever, past year, never. One Muslim student did not answer question about tobacco use, and eight Muslim students did not answer the 
questions about cigarette use. The one Muslim student with missing information on tobacco use reported no cigarette use.

Gambling. Students were questioned about their gambling behaviors in the past school year only. The following forms of gambling were specifically queried: betting on professional sports; betting on college sports; betting on horse or dog races; casino gambling; betting on the lottery or the "numbers;" internet betting or gambling; and betting with a bookie, card, dice, or other games of chance while at school. Possible responses included: never, a few times a year, monthly but not weekly, weekly but not daily, daily. For the purpose of this study, the responses were collapsed into the following categories: ever, past year, never. Data was missing for two Muslim participants.

Sexual activity. Participants were asked, "If you have ever been sexually active, has it been with . . " Participants were given the following choices: "I have never been sexually active", "opposite sex", "same sex partner", or "both opposite and same sex partners". For the purpose of this study, the responses were collapsed into the following categories: ever been sexually active or never. In addition, participants were asked, "When you have sexual intercourse, how often do you and your partner use a condom." Possible responses include: never, rarely, sometimes, and always. For the purpose of this study the responses were collapsed into always or sometimes/rarely/never. Analysis was limited to participants who said they had never been married. Data was missing for 16 Muslim students.

\section{Procedures}

The original researchers mailed the survey to students beginning in February 2001. Most students returned the surveys received by May 2001, with five students returning the survey as late as August 2001. The reported response rate was $52 \%$.

\section{Data analysis}

The analysis used weights provided by the original researchers. Descriptive statistics were used to describe the sample characteristics and prevalence of risky behaviors. Chi-square analyses were conducted to test for associations in sample characteristics and prevalence by gender. For bivariate analysis, each risk behavior was analyzed individually, which may result in slightly different sample sizes due to missing data. For non-marital intercourse, the analysis was limited to students who had never been married. Imputation was not conducted as less than $10 \%$ of the data was missing and the sample size was relatively small. For multivariate analysis, logistic regression analysis was used to assess the independent associations with any past year risk taking behavior. Data was 
missing for 2 Muslim students. Associations were summarized as odds ratios (OR) with 95\% confidence intervals (95\% CI).

\section{Results}

\section{Demographic Characteristics}

Of the 10,401 students in the sample, 135 (1.3\%) reported they were raised in Muslim families. The sample of Muslim students was predominately male (65.2\%) and had never married (88.9\%). The sample of Muslim students consisted of: 42.7\% Other, 23.9\% Asian American/Pacific Islander, 23.1\% White, and $10.9 \%$ African-American. Half of the participants (50.4\%) were under 21 years of age, whereas $30 \%$ were between the ages of $22-23$, and $19.3 \%$ of the participants were over 23 years. A majority of students (68.7\%) lived with friends or on-campus housing, compared to the minority (31.3\%) who lived with parents/relatives. The responses on the importance of religious activity varied: $21.8 \%$ not at all important, $18.0 \%$ somewhat important, $27.1 \%$ important, and $33.1 \%$ very important.

\section{Risk behaviors}

Alcohol Use. As previously reported (Abu-Ras et al., 2010), 46.2\% of Muslim students had consumed alcohol in the past year, with no significant difference by gender (males $44.8 \%$ versus females 47.7\%) (Table 1). For the Muslim students who reported drinking, 60\% reporting regular alcohol use began at age 18 or older. To contextualize these results, past year alcohol consumption among non-Muslim students was $80.7 \%$, with over half of individuals (56.1\%) beginning regular consumption at age 18 or older. Among the non-Muslim students, no gender difference in prevalence of alcohol consumption was observed. More in depth analysis of patterns of alcohol use among U.S. Muslim college students within this sample can be found in Abu-Ras, et al. (2010).

Illicit Drug Use. Muslim students past year prevalence of illicit drug use was $24.6 \%$ with no significant difference by gender (males $27.9 \%$ versus females $19.1 \%$ ). Similarly, past year reported marijuana use was $23.9 \%$, with no statistically significant gender difference (males $27.6 \%$ and females $17.0 \%$ ). For the Muslim students reporting marijuana use, 52.4\% indicated their first experience using marijuana occurred before 18 years of age. In order to contextualize these findings, past year prevalence rates for non-Muslim students were $32.9 \%$ for illicit drugs (males $34.5 \%$ versus females $31.4 \%$ ) and $29.8 \%$ marijuana (males $32.1 \%$ versus females $27.9 \%$ ), with gender differences observed for both illicit drugs $(\chi 2=9.9, \mathrm{df}=1, p<.005)$ and marijuana $(\chi 2=21.0, \mathrm{df}=1$, 
TABLE 1. Prevalence of lifetime and past year risk behaviors reported among Muslim students by gender

\begin{tabular}{|c|c|c|}
\hline Behaviors & Lifetime & Past year \\
\hline \multicolumn{3}{|l|}{ Alcohol } \\
\hline Total & 49.2 & 46. \\
\hline Male & 47.1 & 44.8 \\
\hline Female & 52.3 & 47.7 \\
\hline \multicolumn{3}{|l|}{ Illicit drugs } \\
\hline Total & 37.8 & 24.6 \\
\hline Male & 37.0 & 27.9 \\
\hline Female & 38.3 & 19.1 \\
\hline \multicolumn{3}{|l|}{ Marijuana } \\
\hline Total & 31.9 & 23.9 \\
\hline Male & 31.0 & 27.6 \\
\hline Female & 32.6 & 17.0 \\
\hline \multicolumn{3}{|c|}{ Smoking tobacco } \\
\hline Total & 50.8 & 37.3 \\
\hline Male & $58.5^{\star}$ & $43.7^{\star}$ \\
\hline Female & $37.0^{\star}$ & $25.5^{\star}$ \\
\hline \multicolumn{3}{|l|}{ Cigarettes } \\
\hline Total & 45.3 & 37.0 \\
\hline Male & 51.2 & $44.4^{\star}$ \\
\hline Female & 34.8 & $23.9^{\star}$ \\
\hline \multicolumn{3}{|l|}{ Gambling } \\
\hline Total & $\mathrm{n} / \mathrm{a}$ & 30.4 \\
\hline Male & & $36.4^{\star}$ \\
\hline Female & & $19.1^{\star}$ \\
\hline \multicolumn{3}{|c|}{$\begin{array}{l}\text { Sexual intercourse among } \\
\text { never married students } \\
(\mathrm{N}=38)\end{array}$} \\
\hline Total & 53.8 & $\mathrm{n} / \mathrm{a}$ \\
\hline Male & 57.1 & \\
\hline Female & 47.6 & \\
\hline
\end{tabular}

Notes: $\mathrm{n} / \mathrm{a}=$ data not available since not all the behaviors were asked for both the past year and lifetime. Statistical comparisons were conducted for each behavior within Muslim students by gender. ${ }^{\star} p<.05,{ }^{\star *} p<.01,{ }^{* \star *} p<.001$

$p<.001)$. For non-Muslim students, the majority began marijuana use $(64.5 \%)$ prior to turning 18 years.

Tobacco Use. Past year prevalence of tobacco use among Muslim students was $37.3 \%$, with males reporting significantly higher rates than females $(43.7 \%$ versus $\left.25.5 \% ; \chi^{2}=4.30, \mathrm{df}=1, p<.05\right)$. The prevalence of past year cigarette use was $37.0 \%$, with males more likely to report cigarette use than females $(44.4 \%$ 
versus $23.9 \% ; \chi 2=5.31, \mathrm{df}=1, p<.05)$. For Muslim students reporting cigarette use, 55.9\% indicated their first experience began at 18 years or older. To contextualize these results, we also analyzed tobacco use prevalence among nonMuslim students. Among the non-Muslim students $41.4 \%$ report tobacco use (males $47.3 \%$ versus females $36.7 \%$ ) and $34.5 \%$ cigarettes use (males $34.8 \%$ versus females $34.1 \%$ ) with gender differences found only for tobacco use $(\chi 2=118, \mathrm{df}=1, p<.001)$. Unlike the Muslim students, only a minority of nonMuslim students (32.3\%) began cigarette use after 18 years of age

Gambling. Muslim students had past year prevalence of gambling of $30.4 \%$, with higher prevalence among males (36.4\% versus females $19.1 \%$; $\chi 2=4.29$, $\mathrm{df}=1, p<.05)$. Among the Muslim students reporting gambling, a majority $68.8 \%$ reported their first experience was at 18 years or older. To contextualize these findings, non-Muslim students, $42.1 \%$ reported past year prevalence of gambling, with males reporting greater prevalence than females (52\% males versus $33 \%$ females, $\chi 2=368.9, \mathrm{df}=1, p<.001)$, with a majority $(66.6 \%)$ beginning gambling before 18 years of age.

Sexual behaviors. The prevalence of lifetime sexual intercourse among never married Muslim college students was $53.8 \%$, with no significant difference by gender (males $57.1 \%$ and females $47.6 \%$ ). Among sexually active, never married Muslim students, $66 \%$ never to sometimes use condoms during non-marital intercourse. A comparison of condom use by gender among never-married Muslims was not conducted due to small sample size. Information about the age of first sexual intercourse experience was not collected by the original researchers and thus could not be examined. To contextualize the present findings, prevalence of lifetime sexual intercourse among never married non-Muslim students was $68.2 \%$, with no gender difference observed. The prevalence of condom use during sexual intercourse among sexually active, never married non-Muslim students was $46.6 \%$.

\section{Number of risk behaviors}

Approximately 58.5\% of Muslim college students reported having engaged in at least one risk behavior (alcohol use, illicit drug use, tobacco use or gambling, but not sexual intercourse) within the past year (Table 2). No gender difference in mean number of risk behaviors endorsed was observed. Of the individuals engaging in at least one risk behavior during the past year, $77.6 \%$ engaged in two or more risk behaviors. To contextualize these findings, $86.6 \%$ of nonMuslims students engaged in at least one risk behavior within the past year. Of those engaging in past year risk behavior, $72.0 \%$ engaged in two or more risk behaviors.

Logistic regression analyses were conducted to assess the association of measures with any of the four past year risk behaviors (alcohol, illicit drugs, 
TABLE 2. Number of risk behaviors reported by Muslim students by lifetime and past year prevalence

\begin{tabular}{lccc}
\hline Number of behaviors & Past year & Male & Female \\
\hline None & 41.5 & 38.4 & 47.7 \\
One & 18.5 & 18.6 & 18.2 \\
Two & 13.1 & 11.6 & 15.9 \\
Three & 12.3 & 12.8 & 11.4 \\
Four & 14.6 & 18.6 & 6.8 \\
\hline
\end{tabular}

Note: Risk behaviors included alcohol, illicit drugs, tobacco, and gambling.

tobacco, and gambling). Sexual intercourse among non-married students was not included due to lack of data on past year behavior. The independent variables included in the model were gender, living at home (to reflect greater parental monitoring), and religiosity. In the analysis religiosity was found to be independently associated with absence from any risk behaviors in the past year $(p<.05)$. Each one point increase (on the four point religiosity measure) in religiosity was protective against past year risk taking behavior $(\mathrm{OR}=0.60,95 \%$ CI $0.43-0.84)$. Living at home was in the direction of being protective $(\mathrm{OR}=$ $0.58,95 \%$ CI $0.27-1.26$ ) but due to the small sample size was not significant. To contextualize the results, the model was then conducted with non-Muslim students and found that religiosity (OR=0.51, 95\% CI 0.48-.053) and living at home $(\mathrm{OR}=0.58,95 \% \mathrm{CI} 0.51$ - 0.67$)$ were independently associated with engaging in any risk behavior in the past year

\section{Discussion}

This analysis extends our prior research on alcohol use among U.S. Muslim college students (Abu-Ras et al., 2010) to other risk behaviors and provides critically needed baseline data on risk behaviors among U.S. Muslim college students.

Of concern, U.S. Muslim college students reported high levels of risk behaviors, given religious prohibitions. The current findings were comparable to the prevalence rates of illicit drug and tobacco use found among 18-20 year old Scottish Muslims (Bradby \& Williams, 2006). In addition, our hypothesis regarding statistical differences based on gender was only supported for gambling and tobacco. Consistent with our hypothesis, students who engaged in any risk behavior often engaged in multiple risk behaviors. These findings provide additional support to Jessor's (1991) notion that risk behaviors often occur as interrelated clusters. Furthermore, the analysis supports our hypothesis for the protective effect of religiosity against risk behaviors (Haber, Grant, Jacob, Koenig, \& Heath, 2012; Johnson, Sheets, \& Kristeller, 2008; Michalak, Trocki, 
\& Bond, 2007). However, it is important to note that even Muslim students who ranked religious activities as very important also reported risk behaviors.

Although this analysis highlights the prevalence of certain risk behaviors, it cannot address the mediators (e.g., sources of influence, situational factors, functional aspects of risk) that influence engaging in risk behaviors. Hence, additional studies identifying mediators of risk behaviors in American Muslim college students are needed. Potential mediators and moderators include family dynamics (e.g., parent-child communication, family cohesion, parental monitoring, and parenting style), peer relationships (e.g., influence, socialization, peer risk behaviors), neighborhood context (e.g., presence/absence of Muslims and community cohesion), religious community (e.g., degree of interaction, congregational culture), and societal context (e.g., group status, perceived discrimination). In addition, further studies are needed to address mental health outcomes of engaging in risk behaviors.

This present study highlights that Muslim students are not immune to engaging in risk behaviors and, like other emerging adults, often engage in a cluster of risk behaviors (Jessor, 1991). At present, evidence-based prevention services specifically tailored to Muslim students do not exist. As such, it is imperative that comprehensive, religiously and culturally sensitive prevention and intervention programs be developed to address risk behavior life styles for this population. From prior research (Arfken, Owens, \& Said, 2012), we know that at least some Muslim students exposed to prevention programs in high school considered them irrelevant to their community due to lack of known prevalence estimates of Muslims engaging in risk behaviors. Developed tailored programs must target both males and females, given the lack of significant difference in prevalence rates, however researchers should make sure to explore possible difference in engagement and circumstances that could be incorporated in applied settings. The findings also highlight the need to better understand the functional purpose of the risk behavior with the realization that risk behavior occurs in a larger social context, as suggested by Jessor (1991). For example if a student's use of substance is recreational, a different intervention approach would be used as opposed to student's using substance as a coping mechanism to deal with stress. Importantly, these interventions must begin at the minimum in high school and continue throughout college because a substantial proportion of students reported first time use of regular drinking, marijuana, and cigarette use prior to college.

Despite the numerous implications of the current findings, there are also some limitations. Specifically, the sample size of Muslim students was small and analysis was limited by using a secondary data source. As such we did not know country of birth/immigration status of participants, current religious practice, and presence of other Muslims on campus. In addition, the data was collected in 2001, prior to the events of September 11, 2001 which resulted in 
increased attention on Muslims in America. Lastly, water pipe smoking, an increasingly popular risk taking behavior among college students in general and Muslim students in particular (Abu-Ras et al., 2012) was not reported in the public access database and should be included as a form of tobacco use in future studies. These limitations emphasize the need for a new survey to update and expand the present findings to develop appropriately tailored prevention programs.

\section{References}

Abu-Ras, W., Ahmed, S., \& Arfken, C. (2010). Alcohol use among US Muslim college students: Risk and protective factors. Journal of Ethnicity in Substance Abuse, 9, (3), 206-220. http://dx.doi.org/10.1080/15332640.2010.500921

Abu-Ras, W., Ahmed, S., \& Arfken, C. L. (June, 2012). Hookah use among Muslim U.S. college students. Presented at the annual meeting for the College on Problems of Drug Dependence, Palm Springs, CA.

Ahmed, S. (2012). Adolescent and emerging adults. In S. Ahmed \& M. M. Amer (Eds.), Counseling Muslims: Handbook of mental health issues and interventions (pp.251280). New York, NY: Routledge.

Amundsen, E. J., Rossow, I., \& Skurtveit, S. (2005). Drinking pattern among adolescents with immigrant and Norwegian backgrounds: A two-way influence? Addiction, 100, 1453-1463. http://dx.doi.org/10.1111/j.1360-0443.2005.01177.x

Arfken C. L., Ahmed, S., \& Abu-Ras, W. (2013). Respondent-driven sampling of Muslim undergraduate U.S. college students and alcohol use: Pilot study. Social Psychiatry and Psychiatric Epidemiology, 48(6), 945-953. http://dx.doi.org/10.1007/ s00127-012-0588-4

Arfken, C. L., Owens, D., \& Said, M. (2012). Binge drinking among Arab/Chaldeans: An exploratory study. Journal of Ethnicity in Substance Abuse, 11(4), 277-293. http://dx.doi.org/10.1080/15332640.2012.735163

Atkinson, J., Sharp, C., Schmitz, J., \& Yaroslavsky, I. (2012). Behavioral activation and inhibition, negative affect, and gambling severity in a sample of young adult college students. Journal of Gambling Studies, 28(3), 437-449. http://dx.doi. org/10.1007/s10899-011-9273-x

Boyd, C. J., McCabe, S. E., \& Morales, M. (2005). College students' alcohol use: A critical review. Annual Review of Nursing Research, 23, 179-211.

Bradby, H., \& Williams, R. (2006). Is religion or culture the key feature in changes in substance use after leaving school? Young Punjabis and a comparison group in Glasgow. Ethnicity and Health, 11(3), 307-324. http://dx.doi. org $/ 10.1080 / 13557850600628372$

Chédebois, L., Régner, I., van Leeuwen, N., Chauchard, E., Séjourné, N., Rodgers, R., \& Chabrol H. (2009). Relative contributions of acculturation and psychopathological factors to cannabis use among adolescents from migrant parents. Addictive Behaviors, 34 (12), 1023-1028. http://dx.doi.org/10.1016/j.addbeh.2009.06.011

Factor, R., Kawachi, I., \& Williams, D. R. (2011). Understanding high-risk behavior among non-dominant minorities: A social resistance framework. Social Science and Medicine, 73(9), 1292-1301, doi: 10.1016/j.socscimed.2011.07.027. 
Ghandour, L. A., Karam, E. G., \& Maalouf, W. E. (2009). Lifetime alcohol use, abuse, and dependence among university students in Lebanon: Exploring the role of religiosity in different religious faiths. Addiction, 104 (6), 940-948. http://dx.doi. org/10.1111/j.1360-0443.2009.02575.x

Glied, S., \& Pine, D. S. (2002). Consequences and Correlates of Adolescent Depression. Archives Pediatric Adolescent Medicine, 156(10), 1009-1014. http://dx.doi. org/10.1001/archpedi.156.10.1009

Haber, J. R., Grant, J. D., Jacob, T., Koenig, L. B., \& Heath, A. (2012). Alcohol milestones, risk factors, and religion/spirituality in young adult women. Journal of Studies on Alcohol and Drugs, 73(1). 34-43.

Higgins, J. A., Mullinax, M., Trussell, J., Davidson, J. K., Sr., \& Moore, N. B. (2011). Sexual satisfaction and sexual health among university students in the United States. American Journal of Public Health, 101(9), 1643-1654. http://dx.doi.org/10.2105/ AJPH.2011.300154

Islam, S. M. S., \& Johnson, C. A. (2003). Correlates of smoking behavior among Muslim Arab-American adolescents. Ethnicity \& Health, 8(4), 319-337. http://dx.doi. org/10.1080/13557850310001631722

Jayakody, A., Sinha, S., Tyler, K., Khadr, S. N., Clark, C., Klineberg, E., . . . Viner, R.M., (2011). Early sexual risk among black and minority ethnicity teenagers: A mixed methods study, Journal of Adolescent Health, 48(5), 499-506. http://dx.doi. org/10.1016/j.jadohealth.2010.08.010

Jessor, R. (1991). Risk behavior in adolescence: A psychosocial framework for understanding and action. Journal of Adolescent Health, 12, 597-605. http://dx.doi. org/10.1016/1054-139X(91)90007-K

Johnson, T., J. Sheets, V. L., \& Kristeller, J. L. (2008). Identifying mediators of the relationship between religiousness/spirituality and alcohol use. Journal of Studies on Alcohol and Drugs, 69 (1), 160-170.

Johnston, L. D., O’Malley, P. M., Bachman, J. G, \& Schulenberg, J. E. (2012). Monitoring the future national survey results on drug use, 1975-2011: Volume II, College students and adults ages 19-50. Ann Arbor, MI: Institute for Social Research, The University of Michigan.

LaBrie, R. A., Shaffer, H. J., LaPlante, D. A., \& Wechsler, H. (2003). Correlates of college student gambling in the United States. Journal of American College Health, 52(2), 53-62. http://dx.doi.org/10.1080/07448480309595725

Lawrence, D., Mitrou, F., Sawyer, M. G., \& Zubrick, S. R. (2010). Smoking status, mental disorders, and emotional and behavioural problems in young people: Child and adolescent component of the National Survey of Mental Health and Wellbeing. The Australian and New Zealand Journal of Psychiatry, 44(9), 805-814.

Luczak, S. E., Corbett, K., Oh, C., Carr, L. G., \& Wall, T. L. (2003). Religious influences on heavy episodic drinking in Chinese-American and Korean-American college students. Journal of Studies on Alcohol, 64 (4), 467-471.

Luczak, S. E., Shea, S. H, Carr, L. G., Li, T. K., \& Wall, T. L. (2006). Binge drinking in Jewish and non-Jewish white college students. Alcoholism: Clinical and experimental research, 26(12), 1773-1778. http://dx.doi.org/10.1111/j.1530-0277.2002. tb02483.x

Mason, W. A, \& Windle, M. (2002). A longitudinal study of the effects of religiosity on adolescent alcohol use and alcohol-related problems. Journal of Adolescent Research, 17 (4), 346-363. http://dx.doi.org/10.1177/07458402017004002

Michalak, L., Trocki, K., \& Bond, J. (2007). Religion and alcohol in the U.S. Na- 
tional Alcohol Survey: How important is religion for abstention and drinking? Drug and Alcohol Dependence 87, 268-280. http://dx.doi.org/10.1016/j.drugalcdep.2006.07.013

Mokdad, A. H., Marks, J. S., Stroup, D. F., \& Gerberding, J. L. (2004). Actual causes of death in the United States, 2000. Journal of the American Medical Association, 291, 1238-1245. http://dx.doi.org/10.1001/jama.291.10.1238

O'Malley, P. M., \& Johnston, L. D. (2002). Epidemiology of alcohol and other drug use among American college students. Journal of Studies on Alcohol (Suppl. 14), 23-39.

Substance Abuse and Mental Health Services Administration. (2011). Results from the 2010 National Survey on Drug Use and Health: Summary of national findings (NSDUH Series H-41, HHS Publication No. (SMA) 11-4658). Rockville, MD.

Wechsler, H. Harvard School Of Public Health College Alcohol Study, 2001 [Computer file]. ICPSR04291-v2. Boston, MA: Harvard School of Public Health [producer], 2005. Ann Arbor, MI: Inter-university Consortium for Political and Social Research [distributor], 2008-02-05. doi:10.3886/ICPSR04291.

Wechsler, H., Lee, J. E., Kuo, M., \& Lee, H. (2000b). College binge drinking in the 1990s: A continuing problem: Results of the Harvard School of Public Health 1999 College Alcohol Study. Journal of American College Health, 48(5), 199-210. http:// dx.doi.org/10.1080/07448480009599305

Wechsler, H., Lee, J. E., Kuo, M., Seibring, M., Nelson, T. F., \& Lee, H. (2002a). Trends in college binge drinking during a period of increased prevention efforts: Findings from 4 Harvard School of Public Health College Alcohol Study Surveys: 1993-2001. Journal of American College Health, 50 (5), 203-217. http://dx.doi. org/10.1080/07448480209595713

Wechsler, H., Lee, J. E., Nelson, T. F., \& Kuo, M. (2002b). Underage college students' drinking behavior, access to alcohol, and the influence of deterrence policies: Findings from the Harvard School of Public Health College Alcohol Study. Journal of American College Health, 50 (5), 223-236. http://dx.doi. org/10.1080/07448480209595714

Wechsler, H., Nelson, T. F., Lee, J. E., Seibring, M., Lewis, C., \& Keeling, R. P. (2003). Perception and reality: A national evaluation of social norms marketing interventions to reduce college students' heavy alcohol use. Journal of Studies on Alcohol 64(4), 484-494.

Zaleski, E. H., \& Schiaffino, K . M. (2000). Religiosity and sexual risk-taking behavior during the transition to college. Journal of Adolescence, 23(2), 223-227. http:// dx.doi.org/10.1006/jado.2000.0309 